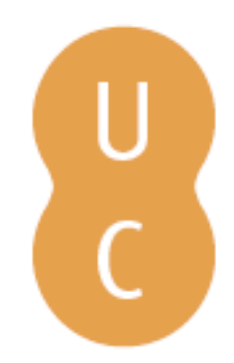

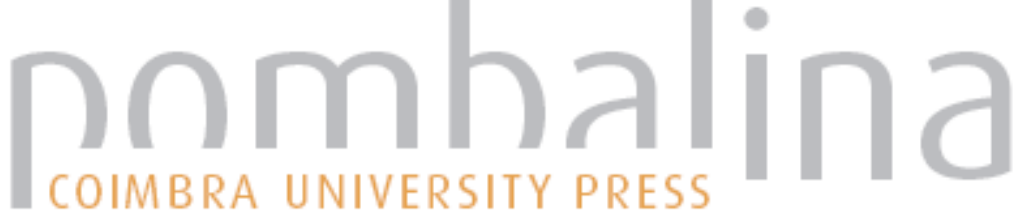

\section{Os Jogos Olímpicos na Grécia Antiga: um certame de ideal e de glória}
Autor(es):
Silva, Maria de Fátima
Publicado por: Imprensa da Universidade de Coimbra
URL
persistente:
URI:http://hdl.handle.net/10316.2/38366
DOI:
DOI:http://dx.doi.org/10.14195/978-989-26-0371-1

Accessed : $\quad$ 26-Apr-2023 11:30:47

A navegação consulta e descarregamento dos títulos inseridos nas Bibliotecas Digitais UC Digitalis, UC Pombalina e UC Impactum, pressupõem a aceitação plena e sem reservas dos Termos e Condições de Uso destas Bibliotecas Digitais, disponíveis em https://digitalis.uc.pt/pt-pt/termos.

Conforme exposto nos referidos Termos e Condições de Uso, o descarregamento de títulos de acesso restrito requer uma licença válida de autorização devendo o utilizador aceder ao(s) documento(s) a partir de um endereço de IP da instituição detentora da supramencionada licença.

Ao utilizador é apenas permitido o descarregamento para uso pessoal, pelo que o emprego do(s) título(s) descarregado(s) para outro fim, designadamente comercial, carece de autorização do respetivo autor ou editor da obra.

Na medida em que todas as obras da UC Digitalis se encontram protegidas pelo Código do Direito de Autor e Direitos Conexos e demais legislação aplicável, toda a cópia, parcial ou total, deste documento, nos casos em que é legalmente admitida, deverá conter ou fazer-se acompanhar por este aviso.

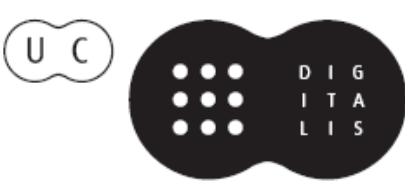


FRANCISCO DE OLIVEIRA

Coordenação

Ospírito Olímpico

no

novo milénio 


\section{OS JOGOS OLÍMPICOS NA GRÉCIA ANTIGA. \\ UM CERTAME DE IDEAL E DE GLÓRIA}

Maria de Fát ima Sil va Universidade de Coimbra

Reflectir sobre os grandes jogos que concentraram as atenções do mundo helénico e, por essa mesma dimensão e prestígio, foram capazes de deixar o seu lastro vivo para além deste segundo milénio prestes a findar, é, de alguma maneira, revitalizar diversos motivos que foram fulcrais no que chamamos 'espírito grego'. O recuo que se torna necessário fazer até às suas origens - ainda que, pela própria dimensão dos séculos, nos quedemos mergulhados em sombras e hesitações insolúveis -, à procura de uma luz sobre o embrião de um processo destinado a tão largo futuro, transmite-nos, pelo meio das dúvidas, sinais luminosos; o carácter sacro impõe-se, antes de mais, como o contexto permanente, onde os deuses dominam, na condução dos destinos humanos, e onde permitem, por um momento que a sensatez reduz à fugacidade de um raio, que o homem se eleve acima da sua natural efemeridade e pequenez. Que, em certas ocasiões, os jogos simbolizem homenagem aos mortos, heróis ou amigos, que o destino conduziu à outra margem da existência universal onde reinam as sombras, não deixa de ser um contacto com outros horizontes que os deuses igualmente regem, não sem que uma quota de relação humana agora se insinue. Depois, à medida que a sociedade helénica foi progredindo de uma fase arcaica e profundamente aristocratizada para outra em que o indivíduo, como membro de uma comunidade social ou polis, se foi impondo, a intenção a presidir à realização dos jogos ganhou também uma amplitude diversa. Reunir o mundo helénico numa festa, onde todos, irmanados 
num mesmo ideal, se congregavam para competir por um prémio de arete e para receber, perante uma plateia pan-helénica e diante da soberania dos deuses, o galardão merecido, tornou-se um momento de união nacional, raro dentro de um conceito de repartição política característico da Grécia antiga. Numa celebração sobre a qual se derramavam todos os efeitos de solenidade e de elevação, o ser humano podia tocar, sem excessos mas com legitimidade plena, a distinção máxima: o dom da glória, traduzido na simplicidade de uma coroa de folhagem, que os deuses lhe depunham por um momento nas mãos, ao som dos aplausos de toda a Grécia reunida em festa. Fugaz o momento que não o seu eco, perpetuado para além do tempo pela voz inspirada dos poetas e pela mão hábil e firme do artista do cinzel. Pela arte dos homens, com a conivência divina, o vencedor ultrapassava os limites estreitos da sua própria essência; porque a vitória desportiva mais não era do que pretexto para êxitos superiores, onde se impunham as coroas, essas de ouro, do espírito.

Do mundo arcaico, de que os Poemas Homéricos são o eterno testemunho, avultam já imagens da realização de jogos ao serviço de diversas intenções. Concebidas, antes de mais, no ambiente denso da guerra, as provas atléticas aproveitam, numa outra dimensão, o próprio potencial físico dos heróis ou o seu adestramento para as exigências do combate. Elas são, portanto, a dimensão pacífica das artes da guerraO. Dois episódios famosos se tornaram paradigmáticos desta prática: os jogos fúnebres com que Aquiles reverenciou a memória de Pátroclo (llíada 23. 257-897) e as provas festivas com que Alcinoo quis desenrugar a fronte e o espírito sofrido do seu hóspede, o Ulisses que muito sofreu (Odisseia 8. 100-130).

Num e noutro caso, a motivação que os dita é ainda de tom individualista e eminentemente aristocrático. O seu alvo é um indivíduo, morto ou vivo, a quem se quer homenagear em nome da amizade ou da simpatia devida a um hóspede. Por trás dos homens, estão os valores que elevam o processo e o colocam ao serviço de um princípio ou ideal.

(') Sobre a diversidade de teorias que, a partir de dados antropológicos ou dos testemOnhos épicos, se multiplicam à procura de uma explicação satisfatória sobre a origem dos jogos, vide M. H. Rocha Pereira, Estudos de História da Cultura Clássica, I, Lisboa, 81998 , p.340. 
Apenas esse não é ainda um factor mobilizador de massas, mas tão só partilhado pelo núcleo estreito de uma elite de heróis gregos em Tróia, ou de nobres comensais na corte dos Feaces.

Depois de prestar as honras devidas ao cadáver de Pátroclo, Aquiles organiza, em homenagem do amigo, provas atléticas. Começa por reunir os prémios que, no ambiente restrito do campo de batalha, são bens materiais, decerto produtos de saque acumulados pelo guerreiro morto, que deverão passar agora às mãos dos vencedores nos jogos em sua honra. A volta reúne os Mirmidões em assembleia, como um público delimitado e específico. Logo se anuncia a primeira prova, a mais nobre, distinta e espectacular de entre todas( $\left.{ }^{2}\right)$, a de carros de cavalos, e já se aprontam os heróis, seduzidos pelo frémito da competição e pelo estímulo dos prémios. Cada um põe ao serviço da prova força e engenho, os mesmos dotes que fazem dele um guerreiro distinto no combate. Mas, para além do empenho humano, estão os deuses que, em cada momento do percurso, dispõem da sorte dos concorrentes. A mão divina, na descrição homérica da prova, está presente, não porque os deuses sejam já os destinatários primeiros dos jogos, mas porque deles disfrutam também, participam e sobretudo decidem com a sua autoridade suprema. Por isso a vitória é a obra cooperante da arete humana com o favor divino. Nenhum poeta foi capaz de traduzir, com mais vigor do que o autor da llíada, o ímpeto da prova. Atento à reacção e ao esforço de cada concorrente, à intervenção directa dos deuses sobre os participantes no agôn - guerreiros, cavalos carros -, o episódio épico põe a tónica na prova desportiva em si, dentro de uma visão que sobretudo premeia o valor físico de cada herói no que é verdadeiramente um concurso de arete individual, entendida como empenho, correcção e desportivismo. Este passo é, portanto, como muito a propósito salienta Harris(3), o embrião de 3000 anos de

(2) Com o curso do tempo, a prova de corrida de cavalos e de carros manteve todo o seu prestígio. Em Olímpia era- Ihe dado um lugar destacado no primeiro dia de provas, como convém a um espectáculo que exigia gastos, mas que oferecia uma exibição notável e proporcionava a vitória mais sedutora. A própria exigência financeira manteve para esta prova um perfil marcadamente aristocrático.

(3) H. A. Harris, Sport in Greece and Rome, London, Thames and Hudson, 1972, p.l 54. Cf. ainda, sobre este passo homérico, V. Vanoyeke, La naissance des jeux olympiques et le sport dans l'Antiquité, Paris, Les Belles Lettres, 1992, p.I 7- 22. 
literatura desportiva. Outros certames se seguem nos jogos oferecidos a Pátroclo: o pugilato, a luta, a corrida, o combate, o disco, o arco e o dardo. Mas nenhum atinge, apesar do valor dos concorrentes, o brilho inimitável da disputa harmónica entre corcéis e seus aurigas.

E em ambiente de paz que os jogos decorrem na terra dos Feaces, organizados pelo soberano Alcinoo para acolher e distrair das suas amarguras evidentes o hóspede recém-chegado, Ulisses. Aos heróis junta- se toda uma multidão curiosa, na ânsia de presenciar e aplaudir as façanhas dos concorrentes, um punhado de cortesãos ou familiares do rei. Dada à prova da corrida a prioridade, outras se seguiram para glória dos vencedores e regozijo da multidão que os saudava, contagiada do entusiasmo colectivo. Mas, neste contexto de recepção e festa, o filho do monarca, Laodamante, não deixou de referir, no convite feito ao hóspede para que participasse, o espírito de elevação que deve ser o verdadeiro motivo de cada concorrente: 'E a tua vez agora, estrangeiro, de participares nos jogos, se conheces alguma modalidade. $E$ deves conhecer. Porque não há para um homem, ao longo da vida, glória maior do que arrebatar uma vitória com os pés e com os braços' (Od. 8. 145- 148).

Presentes numa tradição muito antiga de que os episódios homéricos dão a prova, os jogos aparecem desde muito cedo na vida grega. Posteriormente disseminadas por várias cidades, que internamente organizavam os seus próprios concursos, estas disputas ganharam eco de facto significativo nos grandes agones que, já a partir do séc. VIII a. C., mobilizaram a Grécia inteira num envolvimento pan-helénico. 776 a. C, o ano da realização da primeira olimpíada, o festival mais antigo, mais solene e mais famoso de entre todos, definiu um marco na existência oficial dos jogos desportivos; e 'oficial' passou a pressupor regularidade e exigência de medidas organizativas. Algo do espírito aristocrático se mantinha vivo nesta nova fase: o culto da superioridade física, o gosto pela disputa leal, o desejo de um prémio que distinguisse e impusesse à consideração geral os vencedores. É este um conjunto de objectivos a que a palavra philotimia se aplicaria com propriedade $\left({ }^{4}\right)$. Apenas o 
contexto da disputa e a qualidade dos concorrentes começava a mudar. Não se tratava agora de mobilizar plateias restritas em volta da superioridade incontestada de uns tantos heróis ou herdeiros de casas nobres. Importava mobilizar a Grécia inteira, os povos de todas as cidades, para um encontro onde todos partilhassem de um espírito e de um objectivo comum. Era uma consciência nacional que se desejava impregnar num povo que, por tradição, vivia repartido em pequenos núcleos politicamente independentes e, por alguns dias, fazer-Ihe sentir o peso de uma cultura que os unia, por sobre quaisquer fronteiras físicas ou políticas. Este objectivo tornava-se tanto mais premente quanto, por força de uma explosão populacional, muitos Gregos se viam compelidos a abandonar a sua terra e a procurar um novo espaço para viver. Era a fase da colonização, que dispersava as populações de origem helénica por toda a bacia do Mediterrâneo. Com o curso dos tempos, esta intenção deu os seus frutos; não será inútil transcrever o comentário com que Isócrates se Ihe referia, no cap. 43 do seu Panegírico (5):

Com justiça se elogiam os que instituíram as panegírias, porque nos legaram o costume de nos reunirmos, depois de termos feito libações e de termos deixado os ódios existentes, e, seguidamente, após termos efectuado preces e sacrifícios em comum, de nos lembrarmos do parentesco recíproco, de nos tornarmos de futuro mais benevolentes, de renovarmos laços de hospitalidade de antanho e de contrairmos outros novos.

O mesmo texto de Isócrates serve-nos ainda para valorizar uma outra marca que, desde sempre, se associou a este tipo de certames pan-helénicos: o carácter sagrado que se espelhava de todos os pormenores da sua orgânica e execução. Enumera o autor do Panegírico os rituais - as libações, as preces, os sacrifícios, as tréguas sagradas - que exprimiam, no concreto, a vénia devida aos deuses patrocinadores da festa. Porque a cada grande festival desportivo presidia uma divindade maior do panteão helénico: Zeus olímpico, de pleno direito, ao mais grandioso de todos estes eventos, as Olimpíadas; Apoio, em Delfos, aos Jogos Píticos; Posídon, em Corinto, aos Istmicos; finalmente ainda Zeus 
aos de Nemeia. H. A. Harris(6) acentua o carácter fortemente antropomórfico da religião grega como o justificativo para esta fusão: dentro de uma concepção de divindade à semelhança do homem, os Gregos atribuíam aos seus deuses o mesmo prazer pela música, a dança ou o desporto que eles próprios tiravam dessas actividades. Sagrado, em consequência, o terreno que servia de cenário às provas, o temenos do deus patrocinador, como sagrados e inviolados de conflitos os dias reservados às festividades. Sagradas igualmente as regras que vinculavam cada concorrente na realização das provas, como sacrossanto o juramento com que se comprometiam(7). Todo este clima sacro se repercutia de imediato no ambiente ordeiro, seguro e livre que se desejava garantir a todos desde a partida até ao regresso a casa, por longínqua que fosse. Mas mais do que um objectivo meramente pragmático, o espírito sagrado que tudo envolvia convidava à reflexão e impunha a consciência da pequenez humana, se medida pela grandeza divina. Os deuses em tudo estão presentes, para proteger, para decidir, para partilhar com os homens uma celebração de fronteiras universais. Chegam também para premiar, com a sua insígnia divina, os vencedores. Melhor do que nenhuma outra, a voz de Pindaro, o mais célebre cantor de epinícios, ecoa toda esta magnífica aura de religiosidade (Olímpica 8. I sqq.):

Mãe dos jogos, onde se ganham as coroas tão preciosas quanto o ouro, Olímpia! Senhora da verdade, onde os adivinhos, interrogando a chama dos sacrifícios, questionam Zeus (...) para saber se ele favorece os homens, cuja alma arde de desejo de obter uma vitória distinta e a recompensa dos seus labores.

$\mathrm{Na}$ simplicidade de uma coroa de folhagem, simbolicamente associada ao deus e ao local que enquadra a festa, o vencedor recebe um sinal de adesão de tudo o que é grande, dos deuses, antes de mais, e da própria natureza que o cerca e Ihe condiciona a vida. Por seu lado, a força e a destreza com que se empenha são a sua oferta no altar do

(6) Op. cit., p. 16.

(7) Portadoras de um claro ascendente religioso eram também algumas provas, como as corridas de archotes que tinham celebração em Atenas. 
sacrifício. Unidos em suprema harmonia, deuses e homens, sem que por um momento se perca ou esbata a noção clara da fronteira que os une e os separa, que se traduz no gesto significativo do depor das oferendas no templo do deus enquanto o vencedor se guinda às alturas da fama o galardão humano - e ao toque do divino, que a coroa sagrada pousada nos cabelos simboliza.

Ao lado do sagrado, o mitológico veio trazer também ao processo um traço de magia; portador de distância, de fantasia, de paradigma, o tom lendário que é próprio do mito contribuiu para a redenção do que é simplesmente concreto e humano, e para a sua elevação às alturas do exemplar e do eterno. É com esta maravilhosa harmonia do sacro e do mítico, que Pindaro abre a sua II Olímpica (vv. I sqq.):

Hinos, senhores da lira, que deus, que herói, que varão celebraremos? Em Pisa é Zeus o senhor. Os Jogos Olímpicos, Hércules os criou, como primícias da luta ... ( $\left.{ }^{8}\right)$

A Zeus, soberano em Olímpia, os Gregos associavam Hércules, o herói da força máscula, como o criador dos jogos. A pergunta que, em termos humanos, é de difícil resposta - a quem coube a fundação dos jogos? - recebe, na voz dos poetas, a solução magnífica da harmonia do engenho e da palavra (Pindaro, Olímpica 10. 43 sq.):

Então o valente filho de Zeus, reunindo em Pisa todo o seu exército e todo o saque, traçou, em honra do seu sublime progenitor, o santuário divino. Delimitou, com palissadas, o terreno nu do Altis, e destinou a planície em volta a abrigar a paz dos festins. Ao rio Alfeu prestou homenagem com os doze deuses soberanos. A colina de Cronos destinou este nome. (...) A esta solenidade inaugural assistiram, como convinha, as Parcas e o testemunho único da verdade autêntica, o Tempo. Tempo que, no seu curso, transmitiu à posteridade como Hércules partilhou o saque de guerra e lhe consagrou as primícias, como depois instituiu a festa quinquenal, pela celebração da primeira Olimpíada, e os prémios dados pela primeira vez ao vencedor. 
Por intervenção do herói se definira o espaço de 600 pés, o estádio, cenário das provas atléticas. Como das suas artes saíra também a coroa de oliveira brava, com que um dia sombreara de verde, como artista inimitável, os terrenos descarnados de Olímpia, para dar aos homens o refrigério de uma sombra amiga nos ardores do estio, e aos vencedores o galardão divinamente olímpico da vitória. Pindaro ecoa também esta proeza do filho de Anfitrião (Olímpica 3. I I sqq.) e as regras que, como criador dos jogos, o herói comunicou àqueles que agora são seus árbitros:

Executor das antigas prescrições de Hércules, a de depor acima das pálpebras, em torno dos cabelos, o verde folhagem da oliveira que outrora, das fontes penumbrosas do Istro, trouxe o filho de Anfitrião, memorial magnífico das vitórias nos jogos olímpicos. Conseguiu-a do povo dos Hiperbóreos, servos de Apoio, com palavras persuasivas, quando thes pediu, com coração leal, para o santuário hospitaleiro de Zeus, a árvore que daria sombra à multidão dos visitantes e forneceria as coroas aos atletas.

Tão marcante era a intervenção de Hércules na fundação dos jogos olímpicos que muitos quiseram ver, na personalidade de um herói que, depois de cometer uma proeza, funda uns jogos e os dedica a uma divindade (modelo de que Hércules é um padrão), uma explicação mítica para a origem dos diversos jogos pan- helénicos.

Por fim, ao divino veio juntar-se o humano, na figura de Pélops, o primeiro a colher a coroa da vitória. Por isso, a memória de Pélops ficou para sempre associada à vitória olímpica e o seu túmulo, deposto no temenos, se tornou lugar de veneração. Para alguns, os jogos olímpicos eram mesmo um certame fúnebre em sua honra. Com o filho de Tântalo, a intenção ou o ideal do homem grego entrava nesta carta de alforria mítica que durante séculos consignou o espírito olímpico. Ainda uma vez Pindaro nos ilumina com a prece que Pélops, candidato a um troféu difícil mas de sedução única - a mão da bela Hipodamia -, dirigiu a Posídon no momento da prova (Olímpica l. 70 sqq.):

O grande risco exige um homem de fibra. Já que a morte é inevitável, para quê sentar- se na sombra e consumir em vão uma velhice anónima, 
longe de tudo o que faz a beleza da vida? Não, vou enfrentar esta prova.

Etu, concede- me o sucesso por que aspiro.

A afirmação do poder humano, da sua capacidade de enfrentar os riscos impostos à própria condição, como o ideal de um objectivo que dá o sal à vida e a perpetua para além das sombras, esta é uma filosofia de vida humana que enobrece o homem e de que o cenário olímpico se tornou um palco privilegiado.

Ao mito, que dourou o sentido da celebração olímpica, os poetas foram também buscar o ornamento para envolverem os vencedores, cujos feitos, mais do que simples recordes desportivos, podiam assim ganhar o lustre de uma proeza que só a tradição e a qualidade ancestral inspiram.

Para além do toque divino ou lendário, os jogos comportavam uma quota de aplauso humano, de prestígio pessoal e social que, para um povo sempre à procura da valorização da condição humana, não foi irrelevante. Depois da distinção divina, suprema mas não única, o vencedor colhia com emoção ímpar o reconhecimento geral, aquele geras sempre tão caro aos heróis de antanho.

Em todas as cidades gregas, fora do contexto dos grandes festivais, o desporto ocorria como prática comum ou motivava mesmo pequenos certames locais (cf., e. g., Olímpica 7. 84 sqq.). Em algumas comunidades, como entre os povos dóricos, nunca lhe foi negada a maior relevância. Assim concebida e disseminada, a prática desportiva detinha um enorme poder pedagógico e visava o equilíbrio, fundamental no ser humano, entre corpo e espírito. Mais ainda, como afirma Platão no Banquete 182, a qualidade do ser humano que se obtém por esta forma é apanágio do homem livre e indesejada pelas tiranias ou pela barbárie. Decerto por isso, através de legislação de Sólon, os escravos ficaram afastados dos ginásios, mantendo-se estes recinto da formação de cidadãos perfeitos. Dentro do mesmo espírito, Pausanias (10. 4. I) duvida se uma pequena cidade da Beócia, desprovida de ginásio, mereceria o reconhecimento de uma verdadeira polis; como ainda mais tarde Estrabão (5. 246) deduzia a origem helénica da cidade de Nápoles da existência de um ginásio. Em volta destes espaços, onde a juventude masculina se reunia, desde sempre convergiram os intelectuais que, para além da prática desportiva, 
entreviam na convivência aí garantida um terreno propício à comunicação de ideias e à reflexão de teorias. Não foi por acaso que também Platão e Aristoteles preferiram a vizinhança de Acádemo ou do Liceu para instituírem as suas escolasW. Em última análise, a prática física, com os objectivos elevados que comporta ao lado da convivência humana que proporciona, é também ela responsável pela individualidade nacional de um povo.

Com a vitória olímpica, o atleta colhe prestígio para si próprio e, através da sua pessoa, para a família a que está ligado e para a cidade a que pertencei10). Todos participam do êxito obtido: a família, pelo que transmite de dons naturais, que são a marca das raças superiores; mas como é de um estado que depende a sobrevivência e projecção das famílias, a cidade está presente no contributo elementar que também ela dá para a formação e para o enobrecimento do indivíduo. Por isso, a comunidade social se empenha, por todas as vias, em manifestar ao herói o seu reconhecimento e apreço. Distinções materiais, por vezes preciosas, podem contribuir para o bem-estar imediato e concreto do vencedorú'); mas mais do que o provento material, são os sinais honoríficos os que se multiplicam e brilham com fulgor particular. Segundo o testemunho de Plutarco, um gesto como rasgar uma fenda na muralha da cidade para acolher, em glória, um cidadão vitorioso pôde algum dia exprimir a vénia colectiva ao prestígio de um atleta.

Para além da expressão que teve neste diálogo mútuo entre o atleta e a sua cidade, o prestígio olímpico dilatou-se a um plano verdadeiramente pan-helénico. Não é de somenos o estabelecimento de um calendário olímpico, que se mede por períodos de quatro anos

(9) M. Pohlenz, LVomo Creco, trad. italiana, Firenze, reimpr. 1967, p. 809 sq.

(10) Cf., para além dos louvores com que Pindaro associa indivíduo, família e cidade nos seus epinícios, as menções frequentes que se repetem nas Histórias de Heródoto. Aí, a referência às vitórias olímpicas é um elemento indispensável no retrato dos políticos mais distintos: vide, e. g., 6. 34-36, sobre Milcíades, 6. 70, sobre Demarato, 6. 103, sobre Címon, irmão de Milcíades, 6. 122, sobre o ateniense Cálias, ou 6. 126, sobre o avô do democrata Clístenes, com o mesmo nome. Nestes diversos casos, é notória a relação entre os membros das famílias mais distintas, pelo nome ou pela fortuna, com as corridas de carros de cavalos.

(H) A cidade de Atenas, por exemplo, reservava aos vencedores e seus descendentes as honras do Pritaneu. 
correspondentes a cada espaço entre Olimpíadas e que mereceu, como designação identificativa, o nome do vencedor na corrida do estádio (c. 200m). Esta era, de facto, a única cronologia considerada válida na Grécia inteira, a partir da instituição dos jogos. De olhos postos em Olímpia modelaram-se os outros grandes certames pan-helénicos, que Ihes repetiram o espírito e as regras. Mas sobretudo o tempo das olimpíadas, com o seu dom de reunir o povo grego, tornou-se atractivo para todos os que tinham algum produto a oferecer à colectividade. Primeiro os atletas, naturalmente, que se propunham abrilhantar a festa com a agilidade e destreza do corpo. Mas também os intelectuais que vinham fazer demonstração dos seus saberes ou superiores qualidades. Tal como em volta de qualquer comum ginásio se reuniam aqueles para quem os dons do espírito representavam preocupação suprema, em Olímpia era toda a Grécia que fazia demonstração do seu saber. Sofistas e oradores principalmente encontravam em Olímpia um espaço propício à publicitação das suas ideias e palavras: o célebre Hípias, que não perdia, em cada olimpíada, a possibilidade de fazer a sua performance retórica (Platão, Hípias Menor 363 c- d, 368 b-e), ou o não menos célebre Górgias (Paus. 6. 17. 7-9). Até mesmo os políticos podiam colher aí a vénia mais cara aos seus sucessos. Essa rara emoção experimentou-a Temístocles, o herói ateniense de Salamina, que, poucos anos após (476 a. C.) a batalha que a sua estratégia saldara numa estrondosa vitória para a Grécia, chamava sobre si todas as atenções quando se apresentou em Olímpia para assistir aos jogos (cf. Plutarco, Temístocles 17). Só essa atenção foi compensação suficiente para quem, à custa de muitos sacrifícios, se podia considerar um salvador da pátria. E porque não repetir, na tradução de $\mathrm{M}$. $\mathrm{H}$. Rocha PereiraO²), as palavras de Lísias no Discurso em Olímpia, onde o orador exprime a sua emoção diante daquela 'parada de inteligência no lugar mais belo da Grécia'? Na sua aparente simplicidade, esta observação reúne e proclama todos os valores, humanos e divinos, presentes num lugar que a natureza dotou de uma magia indizível.

Nem as Musas quiseram estar ausentes de Olímpia e vieram, elas também, através da voz dos poetas, trazer o seu contributo de beleza.

02) Op. ciU p.345. 
Com o canto dos seus predilectos, de onde avulta com brilho maior o nome de Pindaro, a fama dos atletas ultrapassa a barreira da morte ou do esquecimento. Para além do momento perecível da vitória, para além das honras imediatas ou das muralhas que se rasgam para dar passagem aos eleitos, ergueram-se os versos dos epinícios, que cobriram de magia e de elevação os triunfos desportivos. Ao lado dos poetas, os artistas plásticos descobriram, na nudez do atleta, a beleza de um corpo viril bem conformado e não se cansaram nunca de o reproduzir na aspereza, habilmente dominada, da pedra. Com PohlenzO3) será legítimo afirmar que 'sem o ginásio, a escultura grega não teria podido atingir a elevação que na realidade conseguiu'. Foi a poetas e artistas que coube o milagre de manter verde, até aos dias longínquos que são aqueles em que vivemos e ao eterno sempre, a coroa da imortalidade. Assim o lembra Pindaro (Olímpica 1. 95- 100):

Em Olímpia se julga a velocidade dos pés e a resistência inquebrável da força. Então ao vencedor, para o resto da vida, cabe o mel da felicidade, graças aos jogos. Uma glória que, para sempre, flui, dia após dia, sem quebras, é um bem supremo para os mortais.

Tudo parecia conjugar-se para delinear um quadro de superior perfeição. Mas a própria maravilha, quase divina, que o homem construiu em Olímpia teve de ser também uma lição de equilíbrio e de sophrosyne, não viesse algum orgulho incauto atrair a malquerença dos deuses. Misturada com os louvores, Pindaro recorda esta prudência cautelar que, aliada à vigilância divina, traz a verdadeira felicidade. Ao celebrar Diágoras de Rodes, vencedor já coroado de múltiplos troféus a que acrescentava a vitória no pugilato, em Olímpia, o poeta remata (Olímpica 7. 89 sqq.):

Zeus, (...), protege este herói a quem os punhos valeram a glória; concede- Ihe o respeito afectuoso de concidadãos e de estrangeiros. Ele segue um caminho recto, inimigo da insolência, e sabe bem como praticar as sábias liç̃es que recebeu dos seus nobres antepassados. Não permitas que se obscureça o renome de toda a posteridade de Calíanax; (...) porque

03) Op. cit, p.813. 
num só instante podem soprar, de quadrantes opostos do céu, brisas contrárias.

O mesmo Diágoras que Cícero (Tusculanas I. 46. III) recordava, levado em ombros pelos filhos, todos eles ganhadores do prémio máximo, no auge da felicidade. Prudente, uma voz se ergueu então de entre a multidão: 'Morre, Diágoras, que aos céus não podes subir!'

Palco de glórias e escola de princípios, Olímpia ergueu-se como o símbolo da consciência e dos ideais de um povo. Pôde, por isso, converter-se numa espécie de referência ou marca identificativa de um carácter nacional. Assim o sentiram os Persas quando invadiram território grego na ânsia de alargamento de um império, como o testaram os Gregos, eles próprios, nessa hora de tremendo desafio à sua resistência e liberdade. E Heródoto o cronista por excelência desta fase da experiência grega. Oriente e ocidente cruzavam armas, num duelo de forças, de interesses e de culturas. A desproporção entre os dois campos era indizível, enormes em número as forças persas que avançavam, ameaçadoras, pelo terreno invadido. Ao poder do mais forte estava subjacente a injustiça, que a ambição gera, numa sede de conquista que tem por norma única poder maior. Ao lado da bandeira da injustiça - perigosa insígnia - Xerxes ostentava outro baluarte, não menos arriscado e agoirento: o do desconhecimento, sobre um povo que abordava com a displicência que merece, ao rico, o mais pobre, ou, ao todo-poderoso, o mais fraco. Entre os Persas, de resto, como Heródoto testemunha, a consideração ia para quem lhes é mais próximo, a distância representava, no seu conceito, a própria nulidade (I. 134. 2-3). Esta lacuna de informação Xerxes preencheu-a já no terreno, perante o inimigo e o seu comportamento, que Ihe pareceram, por várias vezes, estranhos e ridículos. Através dos seus conselheiros ou homens de confiança, o rei foi colhendo imagens fiéis do adversário, como aquela que o grego Demarato Ihe traçou, com o conhecimento que Ihe advinha da própria origem (Heródoto 7. 102):

A Grécia, desde sempre, cresceu na pobreza. Mas a ela associou a superioridade (arete), feita de espírito (sophia ) e de uma lei rigorosa (nomos íschyros). Graças a esses princípios, a Grécia defende-se da pobreza e da sujeição a um senhor. 
Incapaz de compreender a linguagem da pobreza e da liberdade, o persa riu, trocista e superior.

Heródoto multiplica, nesta campanha, quadros sucessivos que condicionam o resultado, à partida ameaçador para o lado grego. E, através desses episódios, vai definindo um mundo de diferenças entre etnias que, pela primeira vez, se sentem próximas e interrogativas uma sobre a outra. E neste espaço de revelação em tempo de crise que os jogos retornam como uma prática que identifica os Gregos. Iminente o combate sangrento das Termópilas, Xerxes à frente de uma mole imensa de guerreiros quis informar-se, através de espias, dos movimentos no pequeno campo inimigo. Soube então, com que perplexidade, que os invadidos se entregavam a jogos gímnicosO ${ }^{4}$ ), enquanto outros penteavam os cabelos (7. 208-209). Esta atitude de extrema dignidade, de quem deseja, na iminência da morte, manter o carácter e a elevação, era também o sinal da diferença entre uma sociedade de homens livres e autónomos de vontade, perante o peso da subserviência instalada entre os bárbaros (cf. supra p. 69). Ao rir, Xerxes manifestava, com o desprezo e uma profunda incompreensão, uma tremenda imprudência.

O episódio teria, mais tarde, repetição, após o combate naval do Artemisio. De novo o sucessor de Dario inquiria de uns transfugas os movimentos adversários, quando colheu esta resposta (8. 26):

Eles responderam que os Gregos celebravam os Jogos Olímpicos e que Ihes era devido assistir às provas gímnicas e hípicas. O Persa quis saber qual era o prémio proposto, pelo qual concorriam. 'A coroa de oliveira' - disseram-lhe - 'que se destina ao vencedor'. Foi então que Tritantecmes, filho de Artábano, exprimiu uma opinião muito sensata, que Ihe valeu porém, da parte do soberano, uma acusação de cobardia. Quando ouviu dizer que o prémio era uma coroa e não dinheiro, não se conteve e declarou, diante de todos: ‘Deus seja louvado, Mardonio! Que

(14) Esta atitude corresponde à prática desportiva generalizada por toda a Grécia, que conserva um claro carácter pedagógico, sendo o desenvolvimento físico um aspecto indissociável da educação com vista à formação plena do indivíduo. Cf. supra p. 65. 
tipo de homens são estes contra quem nos conduziste nesta campanha? Homens que se não disputam pela posse de riquezas, mas em nome da honra?!

Mais uma vez, com o inimigo dentro de portas, os Gregos não abdicaram dos seus hábitos e fizeram questão de opor aos invasores um comportamento coerente com a sua própria identidade.

O desfecho final desta guerra, de uma glória para a Grécia nunca repetida, foi para todos inesperado; não tanto por milagre divino, mas pela sorte de uma disputa de ignorância e saber, de menosprezo e perspicácia. Ao género humano coube, de facto, no resultado, um quinhão decisivo.

Se os jogos olímpicos constituíram, durante séculos, um padrão elevado do espírito grego, a caducidade, em tudo inevitável, lançou- os numa crise que os encaminhou para a extinção. Já no séc. IV a. C., a infiltração acentuada de profissionais entre os concorrentes, que se vinha registando de tempos anteriores, demoliu a noção de ideal de honra que Ihes dava o brilho principal e manchou, da baixeza do lucro, o ambiente sacro. O empenho pessoal e o esforço de participação que movimentavam os cidadãos deram vez à ideia de competição de alto nível ou de espectáculo, que os deixava passivos e na atitude lateral de quem assiste sem participar. Veio depois a corrupção e a indisciplina, o protesto contra o árbitro, o insulto ao adversário, o desrespeito por todas as regras. Mesmo se adulterado o sentido da reunião, o atractivo da festa persistiu e foi como símbolo de uma prática pagã que o imperador Teodósio a extinguiu, em 393. Tais mudanças não passavam de mais um sinal da crise profunda que, entretanto, se apoderou da Grécia.

Sombra de uma memória, os Jogos Olímpicos ressurgiram no mundo moderno por empenho do Barão Pierre de Coubertin, em 1896. Dos seus ascendentes herdaram as competições desportivas e até um certo gosto pela cultura que se vem, por regra, associando a alguns rituais solenes dos jogos. Podem agora, neste universo da comunicação que é o nosso, mobilizar não uma comunidade apenas, mas o mundo inteiro num apelo que é, de facto, centralizador. O cenário sagrado de Olímpia enquadra ainda, simbolicamente, o acender renovado da chama que 
transportam os novos arautos da realização. Falta, porém, o ideal, nesta experiência profissionalizante e neste espírito lucrativo que envolve o desporto nosso contemporâneo. O vedetismo substituiu-se ao sentido de união nacional, como o sentimento do sucesso e da riqueza fácil que produz não deixam lugar ao espírito elevado da honra. Quem sabe a Grécia, com a responsabilidade que the cabe de assumir as Olimpíadas de 2004, tenha ainda o 'espírito grego' suficiente e capaz de produzir outro milagre. 